\title{
PENGEMBANGAN APLIKASI WEB KELAS ONLINE BERBASIS VIDEO UNTUK PEMERATAAN PENDIDIKAN
}

\author{
I Wayan Suardinata ${ }^{1)}$, Devit Suwardiyanto ${ }^{2)}$ \\ 1), 2) Teknik Informatika Politeknik Negeri Banyuwangi \\ Jl.Raya Jember KM13, Labanasem, Kabat, Banyuwangi, 68461 \\ Email :wayan.suardinata@poliwangi.ac.id ${ }^{l)}$, ds@ poliwangi.ac.id ${ }^{2)}$
}

\begin{abstract}
Education is the basic right of every citizen. For that every citizen is entitled to obtain quality education in accordance with the interests and talents it has regardless of social status, economic status, ethnicity, ethnicity, religion, and gender. Educational progress in Banyuwangi District in recent years can be seen from various indicators but it is realized that there is still a gap between public and private schools, between schools in the suburbs and urban areas. The development of information technology including devices, networks and software can be used to overcome the educational gap by developing a web-based massive online open course (MOOC). $M O O C$ is online learning with unlimited amount of participation and open access through the web. This research makes MOOC using NodeJs as backend server, MongoDb as database and AngularJs and Angular Material as front end. In this paper explains the first step of making a simple MOOC using NodeJs, MongoDb and Angular. This web application can be combined with eCommerce and other supporting features.
\end{abstract}

Kata kunci: Education, MOOC, web apps, video streaming.

\section{Pendahuluan}

Pendidikan merupakan hak asasi setiap warga negara. Untuk itu setiap warga negara berhak memperoleh pendidikan yang bermutu sesuai dengan minat dan bakat yang dimilikinya tanpa memandang status sosial, status ekonomi, suku, etnis, agama, dan gender. Pemerataan akses dan peningkatan mutu pendidikan menjadi prioritas wajib pembangunan daerah Kabupaten Banyuwangi, untuk mewujudkan sumber daya manusia yang memiliki kecakapan hidup (life skills). Lebih lanjut, RPJMD Kabupaten Banyuwangi mengamanatkan pendidikan yang bermoral dan berakhlaq, yang mengintegrasikan ilmu pengetahuan, kreativitas, inovasi dan budi pekerti dalam suatu kesatuan.

Kemajuan pendidikan di Kabupaten Banyuwangi dalam beberapa tahun terakhir dapat dilihat dari beberapa indikator antara lain indeks pendidikan, angka melek huruf, rata-rata lama sekolah, angka partisipasi kasar dan angka partisipasi murni pada berbagai jenjang pendidikan. Indikator-indikator tersebut menunjukkan kemajuan capaian pembangunan bidang pendidikan yang telah dicapai Kabupaten Banyuwangi dalam 2 tahun terakhir. Namun demikian, kedepan masih harus dipacu lagi. Target capaian pada tahun-tahun mendatang, indeks pendidikan Banyuwangi serta indikator lainnya diharapkan lebih tinggi dari rata-rata kabupaten kota di Jawa Timur. Di sisi anggaran, sebagai prioritas utama pembangunan daerah, Pemerintah Kabupaten Banyuwangi telah mengalokasikan anggaran dalam prosentase paling besar [1].

Meskipun alokasi anggaran pendidikan cukup besar, namun disadari bahwa masih terjadi disparitas; antara sekolah negeri dan swasta, antara sekolah yang di daerah pinggiran dan daerah perkotaan. Kesenjangan ini dapat dilihat dari beberapa segi meliputi kualitas sarana fisik, kualitas guru, jumlah dan kualitas buku, keterjangkauan biaya pendidikan, jumlah anggaran serta prestasi siswa. 
Perkembangan teknologi informasi meliputi perangkat, jaringan dan perangkat lunak dapat dimanfaatkan untuk mengatasi kesenjangan pendidikan dengan mengembangkan massive online open course (MOOC) berbasis web. MOOC adalah belajar online dengan jumlah partisipasi tidak terbatas dan akses terbuka melalui web. Penelitian ini membuat MOOC dengan menggunakan NodeJs sebagai backend server, MongoDb sebagai database serta AngularJs dan Angular Material sebagai front end. Dalam paper ini menerangkan langkah awal pembuatan MOOC sederhana menggunakan NodeJs, MongoDb dan Angular. Aplikasi web ini dapat digabung dengan eCommerce dan fitur-fitur penunjang lainnya.

\section{Kursus atau Belajar Online}

Kursus atau belajar online adalah teknik belajar dan mengajar dimana interaksi pendidik dan peserta didik dilakukan melalui web browser atau perangkat telepon pintar, yang bisa bisa diakses kapan saja dan dimana saja. Kursus online adalah salah satu bentuk belajar jarak jauh. Peserta didik dapat belajar tanpa harus datang ke sekolah. Waktu belajar juga bisa dipilih sesuai dengan waktu terbaik yang cocok untuk siswa.

\subsubsection{Massive Open Online Course (MOOC)}

Massive Open Online Course adalah belajar online yang ditujukan untuk jumlah peserta yang tak terbatas dan akses terbuka melalui web. MOOC diperkenalkan pertama kali pada tahun 2008 dan mulai popular sebagai salah satu metode belajar pada tahun 2012. Berawal dari model belajar jarak jauh dimana pusat pembelajaran mengirimkan materi melalui pos [2]. Pada tahun 2001, MIT merilis opencourseware yang memberikan kuliah gratis secara online. Setelah itu banyak universitasuniversitas ternama berinisiatif membuat kuliah gratis online. Gambar 1 menunjukkan sejarah perkembangan MOOC.

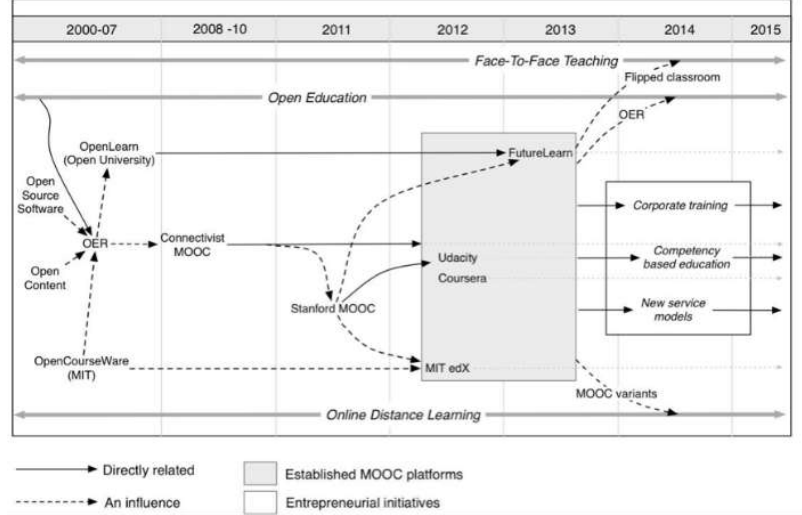

Gambar 1 Sejarah perkembangan MOOC[2]

Awalnya MOOC berisi bahan-bahan ajar seperti video pengajaran, bahan bacaan, dan soal-soal tetapi sekarang sudah menyediakan interaksi antara guru, peserta didik dan asisten pengajar. Tabel 1 menampilkan beberapa daftar penyedia MOOC di luar negeri yang populer.

Table 4 Penyedia MOOC di luar negeri

\begin{tabular}{|c|c|c|c|}
\hline Penyedia & Tipe & \multicolumn{1}{|c|}{ Pusa } & $\begin{array}{c}\text { Regist } \\
\text { rasi }\end{array}$ \\
\hline Stanford & Nirlab & $\begin{array}{c}\text { Ame } \\
\text { rika } \\
\text { Serikat }\end{array}$ & Gratis \\
\hline Coursera & $\begin{array}{c}\text { Kome } \\
\text { rsial }\end{array}$ & $\begin{array}{c}\text { Ame } \\
\text { rika } \\
\text { Serikat }\end{array}$ & $\begin{array}{l}\text { Gratis } \\
\text { Berbayar }\end{array}$ \\
\hline Edx & Nirlab & $\begin{array}{c}\text { Ame } \\
\text { rika } \\
\text { Serikat }\end{array}$ & $\begin{array}{l}\text { Hak } \\
\text { Cipta } \\
\text { dilindung } \\
\text { i }\end{array}$ \\
\hline $\begin{array}{c}\text { OpenClas } \\
\text { sroom }\end{array}$ & $\begin{array}{c}\text { Kome } \\
\text { rsial }\end{array}$ & $\begin{array}{l}\text { Pera } \\
\text { ncis }\end{array}$ & $\begin{array}{l}\text { Hak } \\
\text { Cipta } \\
\text { dilindung } \\
\text { i }\end{array}$ \\
\hline Udacity & Kome & $\begin{array}{l}\text { Ame } \\
\text { rika } \\
\text { Serikat }\end{array}$ & $\begin{array}{l}\text { Gratis } \\
\text { berbayar }\end{array}$ \\
\hline
\end{tabular}

\subsubsection{MOOC di Indonesia}

Penyedia layanan kursus atau belajar online di Indonesia mulai berkembang tetapi yang berbasiskan video masih sangat sedikit. Berikut 
adalah beberapa penyedia layanan kursus atau belajar online:

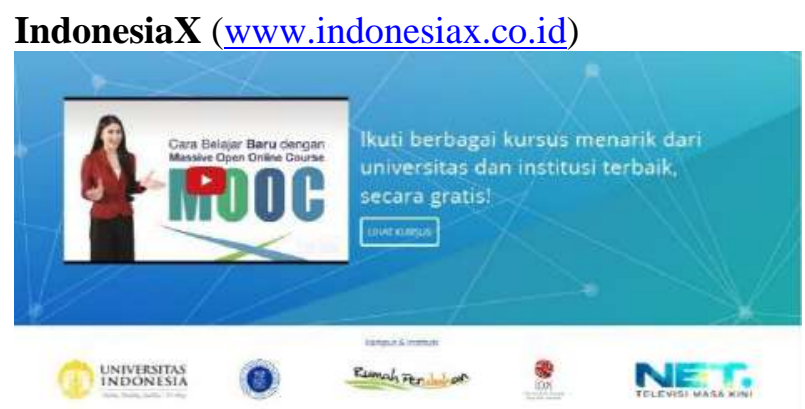

Gambar 2 MOOC IndonesiaX

IndonesiaX adalah suatu inisiatif yang terfokus pada pengembangan edukasi dan pelatihan online berkualitas tinggi di Indonesia. MOOC ini diluncurkan pada tanggal 17 Agustus 2015 bertepatan dengan peringatan kemerdekaan ke-70 Republik Indonesia. Tujuannya adalah untuk memperluas akses masyarakat kepada pendidikan dan keterampilan hidup yang berkualitas melalui sebuah platform kursus online terbuka secara besarbesaran atau massive open online course (MOOC). LMS didesain khusus untuk masyarakat Indonesia dan disajikan dalam bahasa Indonesia. Hal ini dilakukan untuk mengaktualisasikan visi Pemerintah Indonesia dalam meningkatkan akses masyarakat kepada pelatihan bersertifikat dan pendidikan terbaik.

\section{NodeJs, MongoDb dan AngularJs}

NodeJs adalah platform opensource yang memungkinkan kita membuat aplikasi jaringan yang cepat dan berskala besar menggunakan javascript [4]. NodeJs dibuat diatas virtual machine javascript V8, yang merupakan tenaga dari browser Google Chrome. NodeJs dijalankan sebagai aplikasi server. Platform ini menggunakan bahasa pemrograman javascript dan menggunakan teknik non-blockin untuk mempercepat prosesnya. Teknik non-blocking adalah teknik dimana nodeJs akan melakukan eksekusi secara independen. NodeJs akan mengeksekusi sebuah operasi tanpa menunggu operasi sebelumnya selesai.
MongoDb adalah sistem basisdata berorientasi dokumen lintas platform. Diklasifikasikan sebagai basis data "NoSQL", Mongodb menghindari struktur data relasional tabel berbasis JSON yang membuat integrasi data dalam beberapa aplikasi menjadi lebih mudah dan cepat [3].

AngularJS adalah framework aplikasi web yang dikelola oleh Google dan komunitas untuk mengatasi berbagai permasalahan dalam pengembangan aplikasi web. Tujuannya adalah untuk menyederhanakan pengembangan dan pengujian dengan menyediakan framework untuk client-side model-view-controller (MVC) dan model-view-view model (MVVM) beserta komponen-komponen yang sering digunakan dalam pengembangan aplikasi web. AngularJS bekerja dengan membaca halaman HTML yang telah disisipkan custom tag attribute. Angular menterjemahkan atribut tersebut sebagai petunjuk untuk menghubungkan bagian input dan output halaman tersebut dengan model yang direpresentasikan melalui variabel-variabel standar javascript. Nilai javascript tersebut dapat secara manual diset melalui kode atau diambil dari JSON.

\section{OpenEdx (open.edx.org)}

OpenEdx adalah Learning Management System (LMS) yang gratis dan open source yang dikembangkan oleh edX. Platform openEdx digunakan untuk kelas massal (MOOC) maupun dalam modul kelas atau training yang lebih kecil. OpenEdx dikembangkan dengan bahasa python dan MongoDb sebagai basis datanya. Fitur-fitur yang ada dalam openEdx meliputi: open edX studio, open edX LMS, modul xBlock dan forum diskusi.

\section{Basis Data}

Penelitian ini menggunakan rancangan basis data dan alur proses yang dimiliki oleh openEdx . 


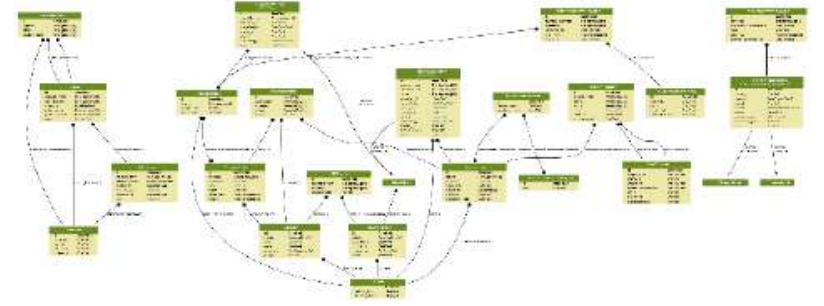

Gambar 3 rancangan basis data

Gambar 3 adalah skema basis data yang diimplementasikan menggunakan basis data MongoDb. Tabel-tabel dalam basis data ini dapat digolongkan menjadi tiga bagian yaitu data user, data kelas dan perkembangannya serta data sertifikat. Detail tabel-tabel tersebut dapat dilihat di halaman web

http://edx.readthedocs.io/projects/devdata/en/latest/i nternal data formats. [5]

Table 2 Tabel auth_userprofile

\begin{tabular}{|l|l|l|l|}
\hline \multicolumn{1}{|c|}{ Column } & \multicolumn{1}{c|}{ Type } & Null & Key \\
\hline id & int(11) & NO & PRI \\
\hline user_id & int(11) & NO & UNI \\
\hline name & varchar(255) & NO & MUL \\
\hline language & varchar(255) & NO & MUL \\
\hline location & varchar(255) & NO & MUL \\
\hline meta & longtext & NO & \\
\hline courseware & varchar(255) & NO & \\
\hline gender & varchar(6) & YES & MUL \\
\hline mailing_address & longtext & YES & \\
\hline year_of_birth & int(11) & YES & MUL \\
\hline level_of_education & varchar(6) & YES & MUL \\
\hline goals & longtext & YES & \\
\hline allow_certificate & tinyint(1) & NO & \\
\hline country & varchar(2) & NO & \\
\hline city & longtext & & \\
\hline bio & varchar(3000) & YES & \\
\hline $\begin{array}{l}\text { profile_image_uplo } \\
\text { aded_at }\end{array}$ & datetime & YES & \\
\hline
\end{tabular}

Sebagai contoh tabel auth_userprofile mempunyai field-field yang ditunjukkan pada tabel 2 dan contoh data auth_userprofile adalah sebagai berikut:

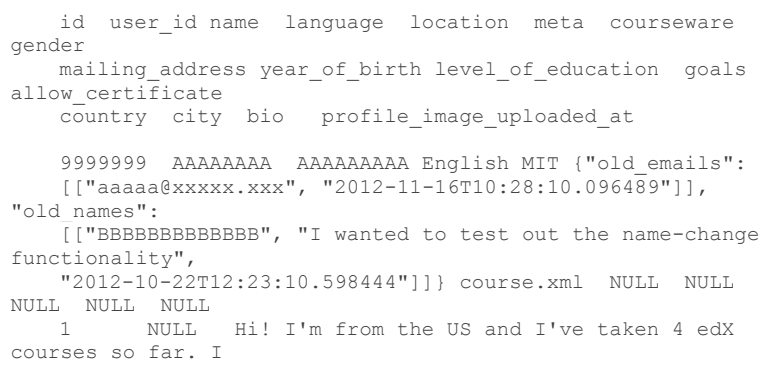

want to learn how to confront problems of wealth inequality. 2016-04-19 16:41:27

\section{Implementasi dan Hasil}

Dengan menggunakan alur proses dan basis data openEdx digabung dengan NodeJs sebagai backend dan AngularJs sebagai frontend, maka dapat diimplementasikan sebuah arsitektur MOOC baru yang berbasiskan javascript seperti terlihat pada gambar 4.

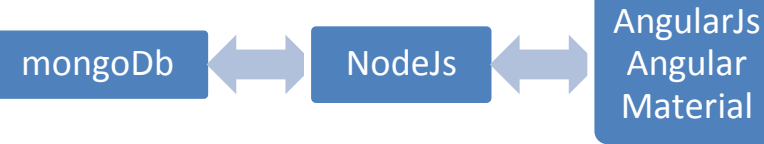

\section{Gambar 4 Arsitektur MOOC berbasis Javascript}

Halaman Utama pada gambar 5 menampilkan promosi semua kelas dalam tiga cara yaitu pada slider besar, slider kecil dibawahnya serta digolongkan berdasarkan kategori. Menu side bar kiri bisa diperkecil sehingga memperluas tampilan untuk belajar.

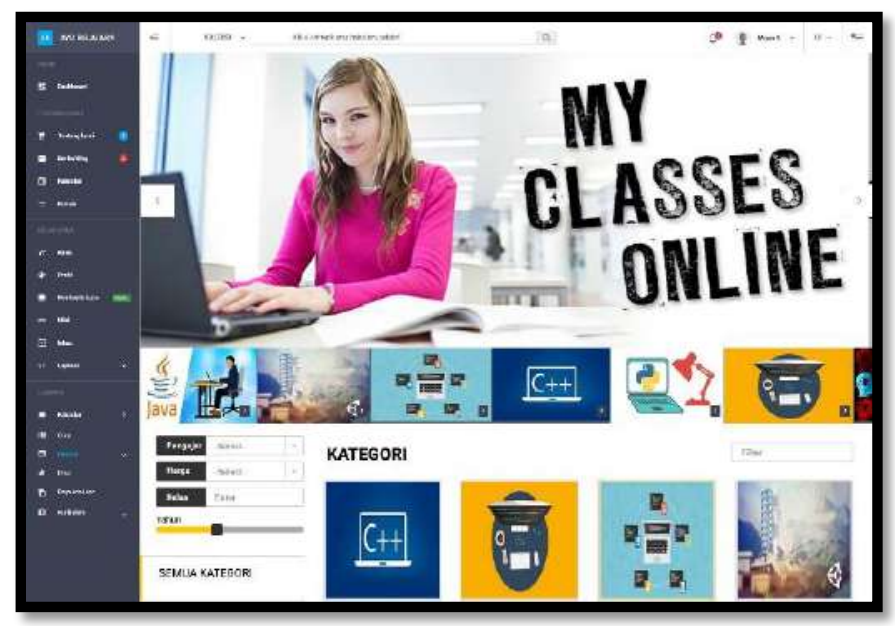

\section{Gambar 5 Halaman utama}

Halaman pencarian pada gambar 6 menampilkan hasil pencarian jika pengguna memasukkan kata kunci pencarian dari halaman utama. Selanjutnya pengguna dapat memperbaiki hasil pencariannya dengan mengatur sub kategori hasil pencarian 


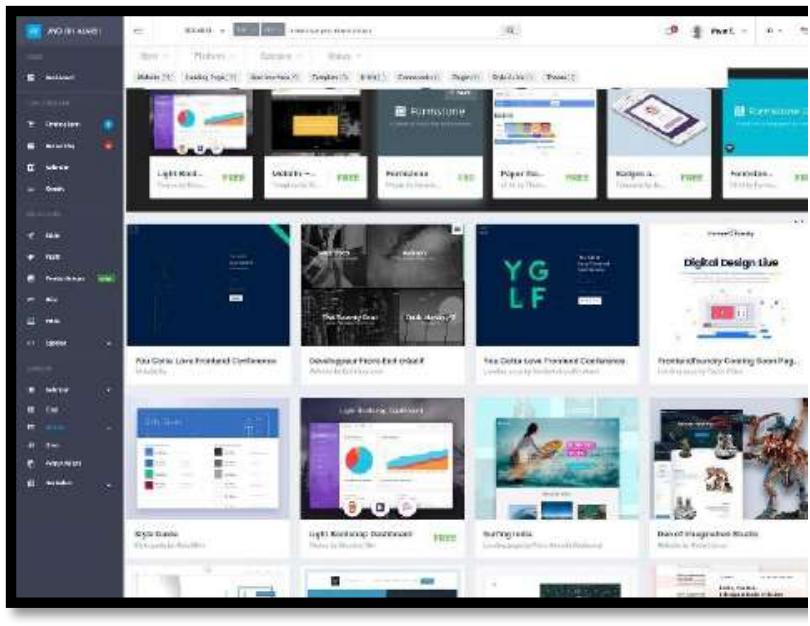

Gambar 6 Halaman Pencarian

Halaman detail kelas pada gambar 7 menampilkan detail kelas meliputi pengajar, deskripsi kuliah dan silabus. Halaman detail akan tampil ketika user memilih sebuah kelas baik dari hasil pencarian maupun dari halaman utama

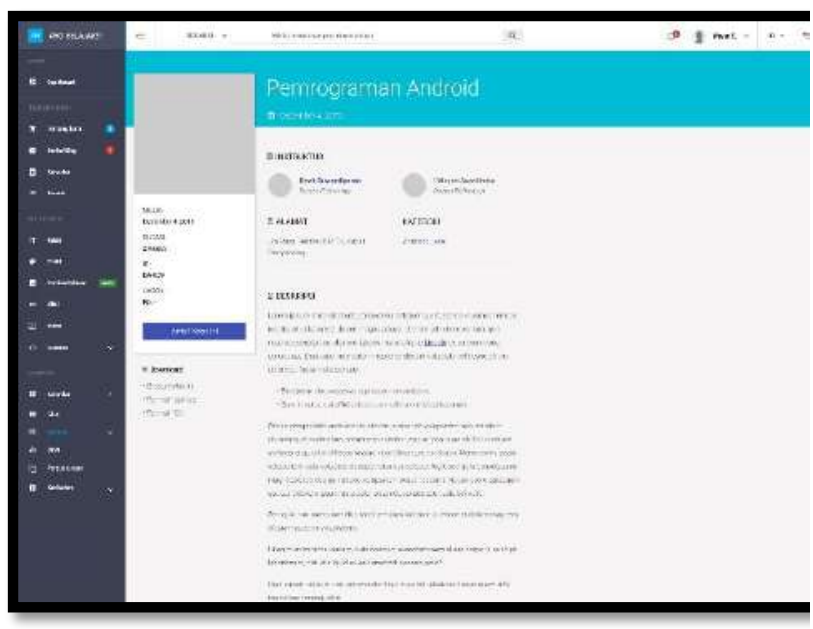

Gambar 7 Halaman Pencarian

Halaman video pada gambar 8 menampilkan ruang belajar siswa terdiri atas daftar isi, ruang video dan sidebar kanan untuk membuat catatan. Fitur lain pada sidebar kanan seperti chat dan kegiatan belum diimplementasikan pada penelitian ini.

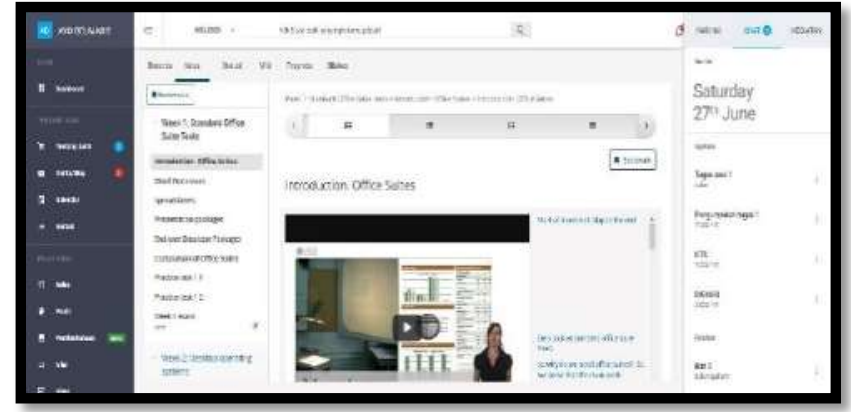

Gambar 8 Halaman Video

\section{Kesimpulan}

NodeJs, mongoDb dan AngularJs dapat digunakan untuk membuat MOOC berbasis javascript. Fungsi-fungsi dasar untuk login, logout, mencari, mendaftar dan mengikuti kelas sudah dapat diimplementasikan dengan beberapa kekurangan. Kekurangan ini dapat diatasi dengan menambahkan error handling dan validasi input sebelum diproses. Aplikasi web kelas online berbasis javascript ini dapat digunakan untuk tahap pertama pengembangan MOOC yang lebih besar baik dari segi jumlah pengguna maupun penambahan fiturfitur lain yang dibutuhkan pengguna.

\section{Daftar Pustaka}

[1] Protokol \& Humas Banyuwangi. 2016. Pendidikan Pro Rakyat Menuju Banyuwangi Cerdas. Diambil dari http://banyuwangikab.go.id/berita/laporan_khusus/pendidikan-prorakyat-menuju-banyuwangi-cerdas.html (15 April 2016)

[2] Jean Charles Pomerol, Yves Epelboin, and Claire Thoury, MOOCs: design, Use and Business Models, London: Wiley, 2015.

[3] Mithun Satheesh, Bruno Joseph D'mello and Jason Krol, Web Development with MongoDb and NodeJs, Birmingham: Pact Publishing, 2015.

[4] Pedro Teixeira, Instant Node.js Starter, Birmingham: Packt Publishing, 2013.

[5] openEdx. 2016. Data Reference. Diambil dari http://edx.readthedocs.io/projects/devdata/en/latest/internal_data f ormats/index.html (2 Desember 2016)

\section{Biodata Penulis}

I Wayan Suardinata, memperoleh gelar Sarjana Komputer (S.Kom), Jurusan Teknik Informatika Institut Teknologi Sepuluh Nopember Surabaya, lulus tahun 2006. Memperoleh gelar Magister Teknik Elektro (M.T.) Program Pasca Sarjana Magister Jaringan Cerdas Multimedia Teknik Elektro Institut Teknologi Sepuluh Nopember Surabaya, lulus tahun 2011.Saat ini menjadi Dosen di Politeknik Negeri Banyuwangi. 
Pengembangan Aplikasi Web Kelas Online Berbasis Video Untuk Pemerataan Pendidikan

Devit Suwardiyanto, memperoleh gelar Sarjana Sains (S.Si.), Jurusan Kimia Universitas Jember, lulus tahun 2005. Memperoleh gelar Magister Teknik (M.T) Program Pasca Sarjana Magister Teknik Elektro Intitut Teknologi Bandung, lulus tahun 2009.Saat ini menjadi Dosen di Politeknik Negeri Banyuwangi. 